\title{
A PRODUÇÃO DE TELEAULAS NO PROCEFET: MÉTODOS, ABORDAGENS E VIVÊNCIAS
}

\author{
Artemilson A. de Lima
}

Departamento de Formação e Ensino Médio - CEFET-RN - Av. Salgado Filho, 1159

\author{
Morro Branco CEP 59.150-000 - Natal-RN
}

artlima@cefetrn.br

\section{RESUMO}

Este artigo discute o processo de produção de teleaulas do PROCEFET (Programa de Iniciação Tecnológica e Cidadania do CEFET/RN). O foco principal da discussão é refletir sobre alguns aspectos relevantes da experiência de produção das teleaulas no ano de 2005, tais como: os métodos; a abordagem didático-pedagógica; algumas vivências do processo de produção; as dificuldades e facilidades desse processo e, por fim, apontar, parcialmente, algumas conclusões que possam servir para o aprofundamento da reflexão, bem como indicadores de futuros trabalhos sobre a temática.

PALAVRAS-CHAVE: Tecnologias da Informação e da comunicação; Teleaulas; Procefet; 


\section{A PRODUÇÃO DE TELEAULAS NO PROCEFET: MÉTODOS, ABORDAGENS E VIVÊNCIAS}

\section{INTRODUÇÃO}

O uso das Tecnologias da Informação e da Comunicação (TIC) nos processos de ensino e aprendizagem tem sido, nas últimas décadas, objeto de reflexão intensa. A urgência de ampliar os espaços de atuação dos sistemas formais de ensino, através dos meios tecnológicos, gera estudos constantes, cujo foco é a adequação e a aplicação das TIC como aliadas indispensáveis, seja no que se refere à consolidação definitiva desses meios nos currículos e projetos político-pedagógicos, seja no tocante à diversificação de sua aplicação, bem como seu papel enquanto instrumentos que asseguram o acesso e a democratização do ensino ao imenso contingente de excluídos dos contextos educacionais, através da educação a distância. Nesse último caso, as contribuições das tecnologias da informação e da comunicação vêm possibilitando uma evolução dos sistemas e indicam uma tendência cada vez mais definitiva: a formação personalizada ou a autoformação. Foi baseado nessa tendência que o CEFET-RN criou o PROCEFET (Programa de Iniciação Tecnológica e Cidadania do CEFET-RN).

O PROCEFET é um programa de educação a distância voltado para os alunos da Rede Pública de Ensino do Rio Grande do Norte que estejam cursando o $9^{\circ}$ ano do ensino fundamental, tenham feito as quatro últimas séries do ensino na rede pública e que almejem ingressar no ensino médio integrado ao técnico do CEFET-RN. A partir de 1993, o Programa passou a ser veiculado pela TV Universitária do Rio Grande do Norte. Durante esses doze anos de existência, variou seu design instrucional. Em alguns momentos, em função dos investimentos que lhe eram feitos - ora relativamente suficientes, considerando seus objetivos; ora escassos, dificultando a ampliação e até mesmo a sua manutenção, obrigando a Instituição a buscar saídas alternativas. Entre 1993 e 1998, funcionou utilizando mídias conjugadas - material impresso, veiculado por um periódico estadual, o Diário de Natal, e teleaulas veiculadas na TV. Entre 1997 e 2004, em função das crises orçamentárias pelas quais passou a Instituição, deixou-se de utilizar a TV e, nos anos de 2002 a 2004 perdeu também o espaço no periódico e atuou através da distribuição de módulos impressos diretamente aos alunos inscritos. Entretanto, a partir de 2005, voltou a ter espaço através da mídia impressa e na TV, veiculando entre junho e outubro de 2005, cinco fascículos impressos pelo Diário de Natal e 18 programas através TV Universitária, sendo cada programa composto por duas teleaulas: Língua Portuguesa e Cidadania e Matemática e Cidadania, totalizando, assim, um número de 32 teleaulas produzidas no próprio CEFET e veiculadas semanalmente na TV Universitária. Em 2005, o PROCEFET funcionou com 3.881 alunos inscritos, sendo 2.218 distribuídos pelo interior do Estado e 1.666 na Capital.

Tencionamos, aqui, refletir sobre alguns aspectos relevantes da experiência de produção das teleaulas no ano de 2005, tais como: a abordagem didático-pedagógica; algumas vivências do processo de produção; as dificuldades e facilidades desse processo e, por fim, algumas conclusões que possam servir como indicadores para futuros trabalhos. 


\section{A TELEVISÃO COMO MEIO EDUCATIVO}

O que diferencia o ser humano dos demais animais, entre outros aspectos, é a sua capacidade de elaborar esquemas de ação sistemáticos, aperfeiçoá-los, ensiná-los, aprendêlos e transferi-los para grupos distantes no espaço e no tempo. Mas não apenas no que diz respeito ao desenvolvimento de artefatos, utensílios e técnicas, como também de tecnologias simbólicas tais como linguagens, escrituras, sistemas de representação icônica etc.; e organizadoras da gestão e da atividade produtiva (SANCHO, 1994).

No mundo contemporâneo, essa capacidade ampliou-se vertiginosamente e resultou num vasto e monumental avanço das tecnologias, principalmente as TIC. Em relação a essas últimas, não apenas no tocante ao refinamento material dos artefatos com a emergência dos sistemas digitais, mas também no que se refere ao aperfeiçoamento das técnicas e dos modelos simbólicos de comunicação e de gestão dos processos comunicativos. Entre tantas tecnologias que foram o centro desse processo, encontra-se a televisão que, além de ter sido um dos meios que mais se aperfeiçoaram do ponto de vista tecnológico, teve o seu acesso paralelamente democratizado. De meio restrito a pequenos e seletos grupos de classe média, até a década de 70 do século passado, tornou-se comum e obrigatório em quase todas as residências brasileiras no início do século XXI. Essa democratização tem acarretado mudanças significativas nos hábitos e na cultura do homem contemporâneo, posto que a televisão passou a ocupar um espaço muito significativo na formação de gostos, definição de padrões de comportamento, redefinição dos discursos, integração de culturas e encurtamento do tempo e do espaço. Nos países industrializados, a televisão chega hoje, a ocupar o terceiro lugar na escala de atividades das populações adultas, perdendo apenas para o trabalho e o sono. Já no que se refere à população infanto-juvenil, essa média sobe de maneira impressionante. Dados do Estúdio General de Médios, na Espanha, por exemplo, atestam que " $96 \%$ das crianças de 4 a 10 anos assistem televisão a cada dia, sendo que 93\% assistem a mais de três horas diárias e para 56\% ela representa a única atividade no tempo livre” (FERRÉS: 1996 pg. 8). È possível aplicar esses dados para a realidade brasileira onde, apesar de tardia, essa influência já atinge proporções idênticas.

Um desafio constante dos educadores de todo mundo tem sido a utilização desse meio como recurso didático-pedagógico, tanto incorporando-o ao cotidiano da sala de aula, a partir do que ele, enquanto meio de comunicação de massa, pode render como objeto de análise crítica, como usando-o como veículo próprio de um processo educativo em programas de caráter aberto ou mesmo em programas educacionais dirigidos, como no caso de cursos de formação a distância através das teleaulas. No centro desse desafio, reside o principal deles: a compreensão da televisão como meio de expressão com características próprias, distintas de outros meios e altamente influente na formação da identidade do homem contemporâneo.

\subsection{Compreendendo o meio}

Hoje, antes de chegar à escola, a criança, além da família, submete-se a um processo educativo que é desenvolvido através da mídia eletrônica, principalmente a televisão, em que é estabelecida uma relação baseada nos estímulos sensoriais, da sedução, da emoção e da narrativa. Os meios de comunicação, em particular a televisão, trabalham com a superposição de linguagens diferentes: imagens em movimento com imagens estáticas; música; texto escrito com texto falado; efeitos sonoros com efeitos visuais, com uma 
narrativa fluída e de lógica pouco delimitada; gêneros, conteúdos e limites éticos pouco precisos (MORAN, 2000).

Nesse sentido, entre os desafios mais importantes na aplicação da televisão aos processos de ensino e aprendizagem situam-se a um só tempo a necessidade de compreensão desse meio no que diz respeito às características socioculturais como também dos aspectos simbólicos inerentes. Esses últimos muito menos visíveis e muito mais influentes. Podemse enumerar alguns: primeiro, a televisão é hoje um poderoso agente de consumo; segundo, trabalha com a possibilidade de gratificação sensorial mental e psíquica; terceiro, trabalha com o viés da vitória do mito da objetividade; quarto, é um poderoso meio de socialização; e quinto, a televisão trabalha com a subliminaridade do discurso ou com a comunicação inadvertida ${ }^{1}$. Em relação à última delas, pode-se dizer que ela oculta mostrando, mostra o que é necessário mostrar, de tal forma que, o que não é mostrado, torna-se insignificante (BOURDIER, 1997). Ou seja, na comunicação televisiva, o telespectador, submetido a um "bombardeio sensorial”, é manipulado de forma fácil, uma vez que esse bombardeio diminui sua capacidade de reflexão consciente e abre espaço para as mensagens inadvertidas ou subliminares (FERRÉS, 1996). É imprescindível levar essas características em consideração quando se opta pelo uso da televisão como instrumento didáticoeducativo dirigido. Esse é o aspecto mais importante a ser considerado, posto que, de certa forma, é através dele que se realizam os demais. Portanto, está na base dos cuidados necessários na formulação dos discursos escritos, orais e visuais, principalmente quando são dirigidos a uma clientela com pouca maturidade e em processo inicial de formação de uma identidade. A compreensão desses e de outros aspectos inerentes ao meio em questão é fundamental para que não se incorra em equívocos no processo de elaboração e produção de materiais didáticos para serem veiculados no formato de teleaulas, ainda que o públicoalvo seja específico, independente do fato da recepção ser livre ou controlada.

\subsection{Panorâmica: os caminhos da televisão na EaD no Brasil}

O uso da televisão para veiculação de teleaulas não se constitui uma iniciativa nova. No Brasil, desde a década de 60, trabalha-se com iniciativas de Educação a Distância utilizando a televisão. Alguns projetos de Televisão Educativa (TVE) aplicada em educação pública foram lançados nas décadas de 60 e 70. Uma parte significativa voltada para a formação de professores e cursos "supletivos", possibilitando aos adultos e adolescentes descompassados do sistema regular, recuperarem-se e completarem seus estudos básicos, Fundamental e do Ensino Médio (ROMISZOWSKI, 2004).

Os telecursos foram até a metade da década de 70, os programas de $\mathrm{EaD}$, em que se utilizava de meios como o rádio e a TV, foram veiculados através da forma de recepção organizada - que incluía formas sistemáticas de estudos com acompanhamento de monitores e tutores -, mas boa parte desenvolveu-se através de metodologias menos rigorosas, chamados de programas de recepção livre.

Nas décadas de 80, 90 e início do século XXI, os programas de EaD pela televisão de maior alcance foram desenvolvidos por iniciativa da Fundação Roberto Marinho, “Os

\footnotetext{
${ }^{1}$ Sobre essas características, poderia ser aprofundado cada um dos aspectos e talvez seja oportuno trabalhálos separadamente. Essas características são, de forma análoga, discutidas com profundidade e minúcia nos livros Televisão e Educação, Televisão Subliminar, ambos de Juan Ferres; Sobre a Televisão, de Pierre Bourdier, e Novas Tecnologias e Mediação Pedagógica, de José Manuel Moran, todos citados nesse artigo.
} 
Telecursos de Primeiro e Segundo Graus" e o “Telecurso 2000”, com a mesma finalidade: proporcionar aos jovens e adultos que estivessem fora de faixa a re-inserção no sistema educacional regular.

O Rio Grande do Norte foi um dos Estados brasileiros pioneiros na adoção de projeto de EaD através da televisão. Um dos projetos de maior destaque na década de 1960, foi o Projeto SACI (Satélite Avançado de Comunicações Interdisciplinares), que pretendia desenvolver cursos completos de primeiro e segundo graus, utilizando mídias integradas TV e rádio. Para isso, foi criada a TVU do Rio Grande do Norte, que inicialmente era ligada ao INPE (Instituto Nacional de Pesquisas Espaciais) e voltada quase exclusivamente para a produção de teleaulas de primeiro e segundo graus e programas para educação infantil. O projeto SACI destacou-se muito mais pela "abordagem sistêmica ao planejamento geral e design instrucional” (ROMISZOWSKI, 2004) e menos pelo seu sucesso e eficácia, posto que, em função de problemas de ordem político-administrativos não chegou a ser implementado como um programa de massa. Outros projetos coetâneos em Estados como Bahia, Maranhão e Amazonas merecem referência.

Entre a década de 70 e a década de 90, alguns programas de cunho educativo de caráter aberto foram produzidos, mas nenhum com um objetivo de terminalidade e programado conforme um design instrucional, posto que eram parte da programação normal da emissora e não vinculados a um programa de EaD. Somente na década de 90, quando foi estabelecida a parceria entre o CEFET-RN e a TVU, é que a emissora passou a veicular teleaulas voltadas para a educação a distância, com a emissão das aulas do então Protécnico que assume a nomenclatura de Procefet no final da década.

\subsection{A Teleaula como instrumento didático-pedagógico}

A teleaula, em um programa de EaD, em geral, funciona como um complemento a outras formas de ensino, utilizando-se outras mídias. Deve, oportunamente, estar vinculada a um projeto de estudos através de material impresso e, de acordo com as condições e design de um curso, a outras mídias, como o computador, através da Internet. De qualquer maneira, o texto escrito, independentemente do suporte, é sempre a fonte mais consistente de estudos que o programa deve dispor e o aluno recorrer. Entretanto, não se pode criar uma hierarquia de graus de importância das mídias, quando se define um design instrucional em um programa de $\mathrm{EaD}$. Nesse caso específico, a leitura e a televisão não podem ser vistas como práticas opostas, ao contrário, devem ser pensadas e trabalhadas de forma complementar, apesar de seguirem padrões comunicativos diferenciados e ativarem processos mentais diversos (FERRÉS, 1998).

O que se recomenda é a busca de um dialogismo que, em última instância, é definidor de um dos princípios mais importantes na EaD: a interatividade. Outro aspecto relevante a ser observado ao se optar pela mídia televisiva como instrumento didático-educativo, é o de que deve-se sempre levar em consideração que um programa educativo e formador, a exemplo da teleaula, precisa adotar características diferenciadas dos demais programas de uma televisão comercial. Uma das recomendações mais comuns é a de que “(...) na produção do material audiovisual, deve-se procurar manter os mesmos critérios dos materiais impressos: enunciados claros e simples, classificação por níveis de dificuldade, conteúdo, assunto, item, subitem, etc.” (FERRÉS, 1998, p. 142). Portanto, o uso educativo da televisão deve ser o oposto do uso do espaço e do tempo televisivo do meio comercial, 
em que o princípio de seleção é a espetacularidade, a sensacionalidade, a grandiloqüência e a dramatização (BOURDIER, 1997), cujas finalidades estão articuladas à sedução para um consumo cada vez mais crescente, o que torna o conteúdo veiculado refém da lógica do mercado e descompromissado com a formação de uma consciência crítica e analítica.

\section{AS TELEULAS DO PROCEFET}

\subsection{Definindo o projeto}

A definição pelo uso da teleaula como mais um recurso didático a ser explorado no Procefet em 2005, se apoiou em experiências passadas, posto que desde 1993, o Programa já havia utilizado esse recurso. Inicialmente com teleaulas diárias, em seguida com teleaulas semanais. Para o ano de 2005, foi firmada uma parceria com a TV Universitária do Rio Grande do Norte, para a veiculação semanal de programas de 30 minutos, distribuídos entre as aulas de Língua Portuguesa e Cidadania e Matemática e Cidadania.

As teleaulas foram produzidas tendo como base os conteúdos dos cinco fascículos elaborados pelas equipes multidisciplinares de professores e veiculados pelo jornal Diário de Natal, adquiridos nas bancas pelos alunos inscritos no Programa. Para cada fascículo, foram produzidos três programas para a TV, num total de quinze. Ao final foram produzidos mais três, sendo dois deles com o objetivo de revisar alguns conteúdos veiculados nas teleaulas normais e um último com orientações gerais aos candidatos.

\subsection{Definindo a abordagem.}

Entre tantas preocupações com a produção das teleaulas, uma mais específica foi a definição de um formato que expressasse sintonia com o público-alvo composto de adolescentes entre 13 e 15 anos de idade, com forte influência da linguagem televisiva comercial e afeitos a uma audiência descompromissada e centrada no caráter de passatempo do meio televisivo.

Nesse sentido, foi importante levar em consideração alguns critérios de utilização dos audiovisuais definidos por (FERRÉS, 1998), entre eles, o conteúdo, o meio, a linguagem, o destinatário e o contexto imediato de assistência.

Como fora definido na fundamentação da proposta de elaboração dos fascículos, os conteúdos de Língua Portuguesa e Cidadania e Matemática e Cidadania seriam trabalhados

\footnotetext{
“[...] numa perspectiva transdisciplinar, e de acordo com a possibilidade oferecida pelo tema gerador de cada fascículo, tentar-se-á estabelecer o diálogo entre as disciplinas, visando a dar ao aluno uma visão complexa (Morin, 1992) do conhecimento, amenizando, assim, o pensamento simplista e redutor tradicionalmente presente no ensino" (PROCEFET, 2005, p. 14).
}

Quanto ao aspecto, conteúdo, quando transposto para o meio televisivo, recebeu um tratamento voltado para a adequação ao meio comunicativo sem deixar de se considerar as especificidades de cada área no tocante às estratégias utilizadas, e sem, contudo, perder de vista as possibilidades de trabalhá-los de forma transdisciplinar. Para isso, os roteiros 
partiram de temáticas e contextos comuns e buscaram abordar os conteúdos através de estratégias didático-pedagógicas comuns.

A formatação do programa foi definida a partir desse princípio, o que influiu na definição da ordem de apresentação. Ficou, então, estabelecido que Língua Portuguesa e Cidadania viriam primeiro e, em seguida, Matemática e Cidadania. Isso, até certo ponto, foi um elemento facilitador na definição de temáticas que eram arroladas e trabalhadas no primeiro programa através numa perspectiva transdisciplinar, uma vez que a mesma temática era desenvolvida por Matemática e Cidadania. Nos dois últimos programas, as professoras/apresentadoras conduziram a apresentação juntas, a partir de temáticas já trabalhadas em programas anteriores, posto que, como já foi dito, esses programas tinham um caráter de revisão.

A eficácia do programa estaria condicionada, em última instância, pela produção de um material audiovisual, com o qual o aluno telespectador se identificasse, sem que se perdesse de vista as características diferenciadas das teleaulas, no que diz respeito à veiculação de conhecimentos sistemáticos e com objetivos didático-pedagógicos dirigidos.

Considerando que a TV, como meio de comunicação de massa, é limitada por espaços de tempo fixos, com horas e a duração da transmissão determinadas (LAASER, 2004), o maior desafio recaía sobre a necessidade de produzir programas, que proporcionasse ao aluno telespectador uma experiência única no seu processo de aprendizagem, utilizando mecanismos que garantissem o aprendizado, independente do material impresso (PROCEFET, 2005). Além disso, era preciso também atentar para o caráter unidirecional da comunicação através da TV, o que, em certa medida, se constituía um desafio ainda maior, posto que um dos aspectos mais importantes nos programas de EAD, é a interação. Como sabemos, a interação não se realiza em uma única via e em uma recepção livre, como a adotada pelo Procefet. Tornou-se necessário, então, buscar mecanismos que garantissem uma audiência sistemática e interessada dos alunos inscritos através de estratégias que aproximassem ao máximo os discursos.

Para atingir tais objetivos, foram definidas três linhas de abordagens: uma relativa à linguagem e adequação dos recursos técnicos comuns num programa de TV comercial para um programa didático-educativo com objetivos fechados e abertos ${ }^{2}$; outra foi a criação e definição de padrões referenciais de identidade com o aluno telespectador; e a terceira concernente à participação direta dos professores especialistas.

A primeira linha refere-se a alguns critérios e conceitos que são condições essenciais para a definição de um formato de teleaulas que viesse a atender às demandas do Programa. Na definição da linguagem audiovisual, três dimensões não poderiam deixar de ser observadas: a dimensão instrumental, que diz respeito ao conhecimento dos recursos formais inerentes ao audiovisual; a dimensão funcional, que, em última instância, determina a função que cada recurso cumpre no momento determinado; e a dimensão do projeto audiovisual, que consiste em compreender o meio - no caso a TV - como veículo de linguagem síntese (FERRÈS, 1998).

\footnotetext{
${ }^{2}$ Os objetivos fechados dizem respeito aos objetivos mais diretos do Procefet, cuja terminalidade é definida pelo alcance da média ponderada entre duas avaliações presenciais realizadas ao longo do Programa e que credencia os alunos a ingressarem na Instituição. Os objetivos abertos podem ser definidos como aqueles que visam a contribuir com a formação mais geral do conjunto dos alunos inscritos, além dos telespectadores voluntários que vêem no programa uma oportunidade de revisão de conteúdos.
} 
Foi igualmente importante observar alguns pontos básicos da teoria da percepção arrolada por Laaser (2004), para apoiar pedagogicamente a produção das teleaulas, cujo postulado básico é o de que

A percepção é, também, mais relativa do que absoluta. Isto significa que nós temos que variar o estímulo para atrair o interesse dos espectadores [...] Se empregarmos uma mudança planejada de técnicas de apresentação tais como ilustrações gráficas, discussões em grupo, cenas da vida real etc., e se usarmos estes diferentes formatos de uma maneira didaticamente estruturada, podemos proporcionar bastante estímulo ao aluno interessado (LAASER 2004: pág. 01)

Seguindo esse princípio, foram estabelecidos alguns padrões de apresentação do programa que ajudassem a criar um ambiente familiar ao aluno telespectador, a partir da primeira teleaula. Assim, definiu-se um padrão gráfico desde a abertura até o encerramento, com vinhetas de passagens identificadas a pontos específicos do conteúdo, de modo a chamar a atenção do aluno, telas com fundos e fontes diferenciadas para Língua Portuguesa e Matemática e cenários temáticos permanentes e alusivos ao ambiente escolar.

A segunda linha de abordagem - a criação e definição de padrões referenciais de identidade com o aluno telespectador -, configurou-se a partir da identificação do perfil social e da faixa etária do aluno inscrito no programa. Como já referenciado acima, o público-alvo das teleaulas eram alunos que tinham entre 13 e 15 anos, cursando a 9a série do Ensino Fundamental, da Rede Pública de ensino. Esse dado foi decisivo na definição do formato. Optou-se, então, pela montagem de um elenco, cujos protagonistas principais eram adolescentes da mesma faixa etária dos alunos inscritos no PROCEFET. Esses alunos-atores, representavam personagens que ora apareciam vivenciando situações cotidianas com os estudos das temáticas e dos conteúdos veiculados pelos fascículos publicados com alguns dias de antecedência - o que permitia ao aluno telespectador um segundo encontro com as temáticas e conteúdos através de uma outra mídia -; ora as situações problemas vividos simuladamente pelos alunos-atores que remetiam à experiência de vida da maioria dos adolescentes, alunos-telespectadores; por fim, a própria imagem dos alunos-atores pretendia criar uma empatia imediata com o alunotelespectador. A maioria dos atores era, praticamente, da mesma faixa etária dos alunostelespectadores e incorporavam personagens de comportamento e posturas supostamente comuns entre eles. Vale ressaltar que um elenco permanente de alunos-atores foi montado utilizando-se os próprios alunos do CEFET-RN, saídos do grupo de teatro da Instituição ou selecionados através de testes feitos antes de iniciarem as gravações dos programas.

Foram, ainda, definidos blocos de abertura, passagens e encerramento protagonizados por dois alunos apresentadores que atuaram como âncoras - um menino e uma menina - que apresentavam, em estúdio, as temáticas de cada programa e conduziam as mudanças de abordagens internas de cada teleaula. Os dois apresentavam-se juntos e atuavam tanto nos programas de Língua Portuguesa e Cidadania, quanto em Matemática e Cidadania.

No tocante ao terceiro aspecto - a participação direta dos professores especialistas -, foram definidos, a princípio, dois espaços de atuação dos professores: um, mais informal, interagindo com os grupos de alunos nos seus locais de encontro - em geral, numa sala fictícia de estudos e centro de aprendizagem presencial ou na biblioteca da Escola; outro, mais formal, no estúdio, resolvendo problemas, explicando os conteúdos e propondo exercícios. Essa forma de envolvimento do professor pretendia criar um ambiente de familiarização, uma vez que eram sempre os mesmos que apareciam, tanto no estúdio, como na interação direta com o grupo de alunos, nos seus locais de estudos. Um aspecto 
facilitador na escolha dos professores especialistas foi o fato de esses professores serem os mesmos que trabalhavam na elaboração dos fascículos e terem, portanto, domínio pleno do conteúdo que estavam apresentando. Alguns, inclusive, já haviam participado dos programas em anos anteriores, o que facilitou ainda mais o trabalho de transposição do conteúdo da mídia impressa para a televisada e o desempenho desses professores diante das câmeras ${ }^{3}$.

\subsection{Linguagens diferentes; caminhos iguais}

Um dos fatores mais desafiadores foi a transposição didática dos conteúdos do formato escrito nos módulos para o formato da teleaula. Não apenas quanto à adequação da linguagem de uma mídia para outra, mas também no tocante à comunicação e ao relacionamento entre as equipes de professores e a equipe de técnicos produtores das teleaulas.

Em relação ao primeiro aspecto, um dos problemas mais comuns, apresentado por Laaser (2006), é o desconhecimento da linguagem audiovisual por parte da equipe de professores que concebem os conteúdos. Em geral, tenta-se transpor os conteúdos expressos na forma escrita sem adequá-los, o que acaba, geralmente, acarretando grandes problemas quanto à eficácia didática do audiovisual, seja ele vídeo ou teleaula. No caso específico das teleaulas do Procefet em 2005, esse problema foi relativamente superado. E um dos aspectos que mais contribuiu para a superação dessas dificuldades, foi o fato de boa parte da equipe de professores já ter relativo conhecimento do formato de teleaulas, adquirido em versões anteriores no próprio programa. Isso facilitou muito o trabalho de transposição e de produção dos roteiros, que também eram concebidos pela mesma equipe de professores que produziam os módulos escritos. Para auxiliá-los foi requisitado o apoio de um estagiário do Curso de Comunicação Social da UFRN. Além disso, foi estabelecida a figura de um mediador, com conhecimentos em didática aplicada à produção de materiais instrucionais através do audiovisual e com grande vivência na área de produção de vídeo, que atuou também como diretor geral do programa e participou ativamente do processo de edição e finalização das teleaulas. Isso, de certo modo, permitiu um diálogo mais fluido entre uma ponta e outra da produção das teleaulas.

Um outro fator determinante nesse processo foi o nível de relacionamento entre a equipe de professores que atuaram nas teleaulas e a equipe de produção. Essa última era composta de um produtor executivo - que também era o coordenador do Departamento de Educação a Distância -, uma produtora dos programas, dois cinegrafistas, um técnico de áudio, dois editores sendo um do CEFET-RN e outro contratado, - uma diretora - contratada -, dois contra-regras e um diretor geral. O relacionamento dessa equipe com os professores foi determinante para o andamento dos trabalhos, tanto no que diz respeito à disponibilidade de ajuda mútua entre a equipe, quanto na capacidade de diálogo com os últimos, de modo que esse se constituiu um dos pilares de sustentação do programa. O fato de ser uma equipe bastante pequena para a realização de um trabalho desse porte, funcionou como estimulante e proporcionou um ambiente rico e vivo, que interferiu positivamente no modus operandi e permitiu um aprendizado mútuo. Considerando as limitações, esse fator foi também determinante para a qualidade final das teleaulas. .

\footnotetext{
${ }^{3}$ Quatro professoras se revezavam na apresentação do programa em estúdio, sendo duas de Matemática e Cidadania e duas de Língua Portuguesa e Cidadania
} 


\section{CONSIDERAÇÕES FINAIS}

A riqueza de uma experiência como essa foi apenas superficialmente retratada nesse breve ensaio, pois seria preciso um mergulho bem mais profundo em aspectos considerados chaves para a compreensão mais nítida do processo como um todo. Aqui, resumiram-se aspectos mais gerais denotadores de uma panorâmica com caráter de apresentação da experiência. Isso não inviabiliza a enumeração de alguns itens conclusivos, ainda que parciais. Entre eles, destaca-se a constatação de que a aplicação e o desprendimento dos profissionais que se envolveram na experiência foi determinante, mediante as grandes limitações, entre as quais podem-se destacar a escassez de recursos humanos e materiais e a exigüidade de tempo para realização. Talvez esse último aspecto tenha sido dos mais determinantes para possíveis falhas que por ventura sejam detectadas numa audiência mais acurada de cada teleaula.

O apoio inquestionável e incondicional das Instituições - o CEFET-RN e a UFRN -, por outro lado, funcionou como atenuante dessas dificuldades e mobilizador do processo.

Em outra via, o empenho e a dedicação dos profissionais que participaram direta e indiretamente das atividades, resultaram num ganho de conhecimentos que só podem ser mensurados na proporção de uma reflexão profunda do processo em questão ou em atividades semelhantes que venham a exigir a aplicação desse conhecimento.

Por fim, esse é um campo vasto e aberto, cujos caminhos irão sempre conduzir a outros caminhos. Cada aspecto discutido neste trabalho, é um campo com possibilidades múltiplas para o desenvolvimento de outros trabalhos. Um deles é a análise de um dos mais importantes aspectos na comunicação em EAD: a recepção. Essa, principal fonte de retroalimentação de qualquer programa de $\mathrm{EaD}$ se apresenta ainda, como um grande desafio para os que fazem o PROCEFET em função do curto alcance do sinal de TV Universitária do Rio Grande do Norte, o que faz com que a maioria dos alunos inscritos, residentes no interior do não tenham oportunidade de assistir às teleaulas, a não ser por meio de DVD's adquiridos individualmente ou através de convênios com as prefeituras de alguns municípios.

Além disso, um campo mais importante relativo à recepção é o significado dessas teleaulas para os alunos da Capital e adjacências, conhecidas como a Grande Natal, que assistem aos programas. O que existe, apesar de importante para a redefinição dos rumos do Programa no formato de teleaulas ainda é vago e restrito ao campo quantitativo.

\section{REFERÊNCIAS BIBLIOGRÁFICAS}

BOURDIER, Pierre. Sobre a televisão. Tradução: Maria Lúcia Machado. Rio de Janeiro. Jorge Zahar Ed., 1997.

BRASIL. Ministério da Educação. Secretaria de Educação Média e Tecnológica.:Programa de inciação tecnológica e cidadania: Procefet. Natal. Ministério da Educação/Secretaria de Educação Média e Tecnológica, 2005.

BRASIL. Ministério da Educação. Secretaria de Educação Média e Tecnológica: Projeto de produção das teleaulas do Procefet. Natal. Ministério da Educação/Secretaria de Educação Média e Tecnológica, 2005. 
FERRÉS, Joan. Televisão e Educação. 2. Ed. Porto Alegre: Artes Médicas. 1998.

FERRÉS, Joan. Televisão Subliminar. Porto Alegre: Artes Médicas. 1999

LAASER, Wolfran. Produção e projeto de vídeo e tv instrucionais em educação a distância. Revista Brasileira de Aprendizagem Aberta e a Distância. $n^{\circ}$. 7-8, editada pelo Instituto Nacional de Educação a Distância. Disponível em: http://www.ufba.br/ crisnova. Acessado em 16 de julho de 2006, às 23:02.

MORAN, José Manuel. Novas tecnologias e mediação pedagógica. Campinas, SP: Papirus, 2000 (Coleção Papirus)

ROMISZOWSKI, Alex. Uma visão histórica - e pessoal - da evolução da Educação a Distância. Educação a distância Editorial. Vol.2/ $\mathrm{N}^{\circ}$ 4: Disponível em: http://www.abed.org.br/publique/cgi. Acessado em: 20 de setembro de 2006, às 20:34.

SANCHO, Juana M. A tecnologia: um modo de transformar o mundo carregado de ambivalência. (in) Para uma tecnologia educacional. Juan Maria Sancho(org). Porto Alegre. Artmed.

SANCHO, Juana M. Pedagogia dos meios audiovisuais e pedagogia com os meios audiovisuais. (in) SANCHO, Juana M. Para uma tecnologia educacional. Porto Alegre. Artmed. 1998. 